\title{
How to Monitor an Interview
}

\author{
DELMONT K. BYRN \\ Associate Professor of Education \\ University of Michigan
}

The now commonplace fishbowl of the counseling laboratory has a glamorous but precarious place in counselor education. The one-way screen or observation window is, at best, a mixed blessing.

To the long established charge that counselors are "technique-happy" can now be added, with at least a grain of truth, the possibility that they have also become "gadget-happy." Just as there has long been the threat of tests dominating the interview, now there is the threat that machines - tape recorders and public address systems - will dominate the counseling laboratory.

No self respecting counselor educator would run a lab without these devices. Neither would he say he is yet getting full value out of the contrivances for the manifold purposes of instruction, supervision and control, not to mention administration and research.

Reactions of the "performer" to these observation devices range from stagefright to showboating, with neither extreme helpful to the counselee. Expectations of the "viewers" range from passive entertainment to the vicarious thrill of spying, notoriously unproductive to either the counselor or the student. However, between these poles lies much room for real learning experience.

The Number One problem in counselor education is not simply getting beyond the textbooks, finding the students, arranging the caseload, or planning case strategy - but, rather, critically supervising the counselor's interview performance so that he can learn something from it.

Attempts of the laboratory director himself to monitor all interviews in progress or to listen to the playback of all recordings is futile in a large-scale program. Whether done individually or in group sessions, only a few interviews can be thoroughly covered each day, what with the director having concurrent administrative, teaching, research, and service duties.

Saying to the practicum enrollee "You're on your own - go to work" is not the answer. While there is no substitute for learning by doing, there are necessary additions to it. As a rule of thumb, any interview that is worth scheduling for learning purposes is worth careful monitoring. 
In addition to the regular counselor education staff there can be added an eschelon of advanced graduate students who are themselves experienced counselors and who have come through the practicum experience, engaged for pay or academic credit to help supervise.

But this still is not enough. In addition to close contact with supervisors, trainees need conferences, and group tape-listening sessions - plus monitoring by fellow counselors. It is this latter possibility that will be discussed further here.

Evaluation of a counseling performance, even if by a not-too-sophisticated colleague, can be helpful to a conscientious counselor. If several monitors give their own version of "quit pushing the student around and listen for awhile," this can be more meaningful - if more threatening than if just one person had suggested it. This would apply as well to successful bits of counselor performance.

Getting fellow counselors in training to monitor each other is not easy. It requires more than developing a rating sheet and saying "start checking." Fact is, the most significant criticisms are likely to be those that objective rating sheets do not accommodate.

Counselors often shy away from individually evaluating their colleague's performance unless they are scheduled to do so, are given practice in doing so, and receive the benefits from the monitoring of their own interviews by their colleagues.

The following kinds of suggestions can serve as a guide to helping beginning supervisors and counselors as they monitor the counseling performance of each other. This applies to monitoring live interviews as well as recording.

1. Schedule all counselors to observe and write monitor reports on a regular basis. This gives purpose to observation and ultimately helps both the performer and the viewer improve their work. An observer need not be an excellent counselor himself to constructively criticize others and to learn in turn from the process. In monitoring the work of advanced counselors, observers should be especially critical. Reports by several monitors on the same performance are more helpful than single reports, even if they are not in agreement.

2. Record both appropriate and inappropriate counseling action. The counselor probably can learn faster by having errors called to his attention, but he should be told of good work as well. To avoid halo effects, assume that each interview is average in overall quality and indicate the good and the bad features as deviations from the average; otherwise there would be no discrimination at the ends of an absolute scale. For errors noted, cite a possible aternative, way to correct the mistake, or to avoid it in the future. 
3. Give suggestions for follow through on anything requiring further attention. Include reminders of things yet to be accomplished in subsequent contacts with the student, such as tying long-range plans into present activities. Call the counselor's attention to any test, publication, reference, person with a recent similar case, or campus facility that might prove helpful. Watch for omissions or missed cues that can be picked up or developed further during subsequent interviews.

4. Observe the needs of the student as much as the counselor performance as such. Evaluate basic adjustment needs and note whether the counselor is helping the student get at them. Check whether the discussion is developing the student's views or those of the counselor. Ascertain whether the student is getting what he came for.

5. Watch for the common counselor shortcomings. These include: asking too many direct questions, paying more attention to facts than to feelings, hurrying by discussion topics without developing them, failing to relate test data to past experiences, discussing future plans to the exclusion of immediate responsibilities, bypassing chances to use student summaries, unduly influencing student decisions, using the same approach to all counseling situations, working toward problem solving without real acceptance, communication, and understanding.

6. Evaluate content as well as methods used during the interview. Most suggestions may be written while the interview is in progress, some may be cited afterwards. Try to evaluate the general counseling style and specific techniques as the counselor probably can improve both. Be sure that technical details, as in test interpretation, do not obscure the broader functions of discussion, such as career exploration.

7. Arrange to make monitoring reports immediately useful to the counselor. Cite a reference for each comment on the monitor sheet so that the counselor can watch for it in replaying the tape. All remarks should be complete and self-contained in the event there is no subsequent direct discussion with the counselor. Reports can be started and ended at any point in the interview, with notations indicating the portion covered. The names of monitors should be recorded so that the counselor can contact him for further discussion.

\section{Monitoring Example}

The following is a reproduction of notes made by an experienced counselor on the reverse side of an objective-type counseling interview evaluation sheet.

(Missed the first 5 minutes of this interview)

"Tell me about school. What do you like best? What courses are you taking?" Ask 
one question at a time and wait for answer. The first lead was good; the others killed it.

Jumped from "school" to "home" to "friends" to "school" without developing any topic well the first time around. Stick with a topic until developed. You'll need to hit several of these again later.

Discussion of "school" seemed pretty teacherish - the kind of discussion teachers would have with each other. Try to "turn him on" and let him describe things in his own words. The series of questions about school "courses? courses last year?, next year? etc." didn't give him much chance to react. Too factual, counselor centered.

Too many direct questions about details of school. Just get him started and visit don't interrogate.

"All in all, school has been going pretty well for you." A good reflection. This is what he had expressed in various ways. Do more of this later on when you get into attitudes and future plans.

"Tell me about your family. How many brothers and sisters do you have?" The second question negated the first. You still don't know about his family as he was too busy answering specific questions. You will want to find out later what work his parents do, what the older brother does - as a general family pattern.

You take stray notes from time to time in a "sneaky" manner - this detracts from the conversation. Actually, you could remember most of these things or pick them up in playing the tape back later. Concentrate more on what he says and develop the idea on the spot - rather than store things away for future reference.

Counselor's squirming and shifting during pauses is passed on to student. Just sit and smile - it'll only be a $3-4$ second wait.

Show enthusiasm about his accomplishments or interests. The "rifle club" topic was worth a more thorough discussion. He would have been glad to tell you more if you hadn't changed to a new topic. Time spent discussing his interests will improve the relationship - make up for the time spent on dull topics of interest only to the counselor.

"You don't think that it is important to work hard now because - - -" Student started to say something here but counselor cut him off to finish sentence. Yield the right-of-way when student volunteers an idea - this is what you've been trving to get started.

"How do you feel about college?" Well done. He responded well to this.

Test selection. Don't talk specific tests. Get him involved in something like "taking an organized look at vour interest patterns" or "checking up on your ability to do college work" or "exploring some of your special aptitudes." You don't need to know exactly what test yourself right now.

"Exploring your future - . -" This is a good general approach, smoothly used here.

His "geology" discussion was given a good hearing by the counselor. This was the best listening of the whole session. This topic should be explored more (Occupational Outlook Handbook and mining engineering pamphlets) but kept in balance with larger possibilities of "science" and "going to college." Try to broaden rather than narrow his occupational goals.

(Had to leave here, for a few minutes, missed the transition to "test taking")

This 20 minute interview was well spent. 45 minutes would have covered more ground. You may want to pursue: summer activities, actual achievement (grades) in school, family educational and occupational patterns more later - after reviewing the personal data blank.

If the above suggestions from a fellow counselor help the performing counselor, well and good. If not, he still can fall back on his own idea of how things went, turn to the tape recording for another run through, or hope the lab instructor himself was around and has a few kind words mixed in with the bad. 